\title{
Square-wave protein-film voltammetry: new insights in the enzymatic electrode processes coupled with chemical reactions
}

\author{
Rubin Gulaboski $^{1}$ - Valentin Mirceski ${ }^{2,3} \cdot$ Milivoj Lovric $^{4}$
}

Received: 4 April 2019 /Revised: 9 June 2019 / Accepted: 9 June 2019

(C) Springer-Verlag GmbH Germany, part of Springer Nature 2019

\begin{abstract}
Redox mechanisms in which the redox transformation is coupled to other chemical reactions are of significant interest since they are regarded as relevant models for many physiological systems. Protein-film voltammetry, based on surface confined electrochemical processes, is a methodology of exceptional importance, which is designed to provide information on enzyme redox chemistry. In this work, we address some theoretical aspects of surface confined electrode mechanisms under conditions of square-wave voltammetry (SWV). Attention is paid to a collection of specific voltammetric features of a surface electrode reaction coupled with a follow-up $\left(E C_{r e v}\right)$, preceding $\left(C_{r e v} E\right)$ and regenerative $\left(E C^{\prime}\right)$ chemical reaction. While presenting a collection of numerically calculated square-wave voltammograms, several intriguing and simple features enabling kinetic characterization of studied mechanisms in time-independent experiments (i.e., voltammetric experiments at a constant scan rate) are addressed. The aim of the work is to help in designing a suitable experimental set-up for studying surface electrode processes, as well as to provide a means for determination of kinetic and/or thermodynamic parameters of both electrode and chemical steps.
\end{abstract}

Keywords Kinetics of electrode reactions and chemical reactions · Surface EC' catalytic mechanism - Surface $\mathrm{EC}_{\mathrm{rev}}$ mechanism · Surface $\mathrm{C}_{\mathrm{rev}} \mathrm{E}$ mechanism · Square-wave voltammetry

\section{Introduction}

In the past three decades, square-wave voltammetry (SWV) emerged as a leading technique in the family of voltammetric methods. Its unique features stem from the specific shape of the applied exciting signal and the current sampling procedure that efficiently discriminates faradaic against charging current [1-5]. Hence, SWV is a highly sensitive voltammetric technique capable to detect miscellaneous analytes at nanomolar concentration level $[6,7]$. Due to the complexity of the potential

Rubin Gulaboski

rubin.gulaboski@ugd.edu.mk

1 Faculty of Medical Sciences, Goce Delcev University, Stip, Macedonia

2 Institute of Chemistry, Faculty of Natural Sciences and Mathematics, POB 162, 1000 Skopje, Macedonia

3 Department of Inorganic and Analytical Chemistry, University of Lodz, Faculty of Chemistry, Tamka 12,, 91-403 Lodz, Poland

4 Divkovićeva 13, 10090 Zagreb, Croatia modulation applied, however, SWV is seldom explored as a technique for mechanistic evaluations. In spite of the fact that numerous theoretical models for various electrode mechanisms are presented so far, a wide application of SWV for kinetic and mechanistic studies is still a challenge. This holds true even for some electrode mechanisms considered to be "simple". For instance, the so-called simple surface confined electrode reaction under conditions of square-wave voltammetry is attributed with rather complex voltammetric pattern [1, 6-10].

Enzymatic electrode reactions in the so-called protein film voltammetry [11-17] are probably the most important examples in the family of surface confined electrode processes. Indeed, electrode mechanisms of uniformly adsorbed redox active biological molecules coupled with follow-up or preceding chemical reactions attract significant attention as they are considered as adequate models for some physiological systems $[7,13,16,17]$. We have presented recently several theoretical models of surface processes coupled to chemical reactions [18-28], revealing a set of intriguing, unique voltammetric features under conditions of SWV. In the present work, a further attempt is made to throw a light to the specific features of surface electrode processes coupled with a follow- 
up, preceding or regenerative chemical reaction. The nomenclature of these systems is surface $E C_{r e v}, C_{r e v} E$ and $E C^{\prime}$ (or surface catalytic mechanism), respectively. The aim of this cumulative work is to help experimentalists to characterize qualitatively particular electrode mechanism and to design a suitable experimental approach for estimation of kinetic and thermodynamic parameters governing surface electrode processes.

\section{Mathematical models}

We consider theoretically four electrode mechanisms adequate to the redox chemistry of firmly adsorbed enzymes in protein-film voltammetry:

1. Simple surface confined electrode reaction $(E)$

$\mathrm{Ox}(\mathrm{ads})+\mathrm{ne}-\stackrel{\mathrm{k}_{\mathrm{s}} \mathrm{P}}{\rightleftarrows} \operatorname{Red}(\mathrm{ads})$

2. Surface confined catalytic (regenerative) electrode mechanism (surface $E C^{\prime}$ )

$\mathrm{Ox}($ ads $)+\mathrm{ne}^{-}-\stackrel{\mathrm{k}_{\mathrm{s} \theta}}{\longleftarrow} \operatorname{Red}($ ads $)$
$\operatorname{Red}($ ads $)+\mathrm{Y} \stackrel{\mathrm{k}_{\mathrm{c}}}{\longrightarrow} \mathrm{Ox}($ ads $)$

3. Surface confined electrode reaction coupled with a follow-up reversible chemical reaction (surface $E C_{r e v}$ )

$\mathrm{Ox}($ ads $)+$ ne $-\underset{\mathrm{k}_{\mathrm{f}}}{\stackrel{\mathrm{k}_{\mathrm{s}}}{\rightleftarrows}} \mathrm{Red}(\mathrm{ads})$
$\operatorname{Red}($ ads $)+\mathrm{Y} \underset{\mathrm{k}_{\mathrm{b}}}{\stackrel{\rightleftarrows}{\rightleftarrows}} \mathrm{Z}($ ads $)$

4. Surface confined electrode reaction coupled with a preceding reversible chemical reaction (surface $C_{r e v} E$ )

$$
\begin{aligned}
& \mathrm{Y}+\mathrm{Z}(\mathrm{ads}) \underset{\mathrm{k}_{\mathrm{b}}}{\stackrel{\mathrm{k}_{\mathrm{f}}}{\rightleftarrows}} \mathrm{Ox}(\text { ads }) \\
& \mathrm{Ox}(\mathrm{ads})+\mathrm{ne}_{\mathrm{s} \theta}-\stackrel{2}{\rightleftarrows} \operatorname{Red}(\text { ads })
\end{aligned}
$$

In all mathematical models, we assume that all species are firmly immobilized on the electrode surface and the mass transfer is neglected. In addition, it is considered that the immobilized species form a uniform monolayer free of lateral interactions. In the schemes (2-4), the symbol " $Y$ " is assigned to an electrochemically inactive compound that is present in a large excess. Consequently, the concentration of $\mathrm{Y}$ is virtually constant at the electrode surface in the course of voltammetry, and all chemical steps in reaction mechanisms (2-4) are considered to be of pseudo-first order. The solution of simple surface electrode mechanism (1) under SW voltammetric conditions can be found elsewhere $[1,7,8,17]$, while the corresponding solutions of the surface $E C^{\prime}, E C_{r e v}$ and surface $C_{r e v} E$ mechanisms are reported in $[1,17-19,26]$, respectively. The recurrent formulas for calculating dimensionless currents $\Psi$ of theoretical SW voltammograms as a function of applied potential are given with Eqs. (5-8):

$\Psi_{\mathrm{m}}:=\frac{\mathrm{K} \cdot \mathrm{e}^{-\alpha \cdot \Phi_{\mathrm{m}}} \cdot\left(1-\frac{1+\mathrm{e}^{\Phi_{\mathrm{m}}}}{50} \cdot \sum_{\mathrm{j}-1}^{\mathrm{m}-1} \Psi_{\mathrm{j}}\right)}{1+\frac{\mathrm{K} \cdot \mathrm{e}^{-\alpha \cdot \Phi_{\mathrm{m}}}}{50} \cdot\left(1+\mathrm{e}^{\Phi_{\mathrm{m}}}\right)}$

(5) is the recurrent formula for mechanism (1) i.e., simple surface redox reaction.

$\Psi_{\mathrm{m}}:=\frac{\mathrm{K} \cdot \mathrm{e}^{-\alpha \cdot \Phi_{\mathrm{m}}} \cdot\left(1-\frac{1+\mathrm{e}^{\Phi_{\mathrm{m}}}}{\mathrm{Kchem}} \cdot \sum_{\mathrm{j}-1}^{\mathrm{m}-1} \Psi_{\mathrm{j}} \cdot \mathrm{M}_{\mathrm{m}-\mathrm{j}+1}\right)}{1+\mathrm{K} \cdot \mathrm{e}^{-\alpha \cdot \Phi_{\mathrm{m}}} \cdot\left(1+\mathrm{e}^{\Phi_{\mathrm{m}}}\right) \cdot \frac{\mathrm{M}_{1}}{\mathrm{Kchem}}}$

(6) is the recurrent formula for mechanism (2) (surface $E C^{\prime}$ ).

$\Psi_{\mathrm{m}}:=\frac{\mathrm{K} \cdot \mathrm{e}^{-\alpha \cdot \Phi_{\mathrm{m}}}-\frac{\mathrm{K}}{50} \cdot \mathrm{e}^{-\alpha \cdot \Phi_{\mathrm{m}}} \cdot \sum_{\mathrm{i}=1}^{\mathrm{m}-1} \Psi_{\mathrm{j}}-\frac{\mathrm{K} \cdot \mathrm{Keq}}{1+\mathrm{Keq}}(\mathrm{Kchem})^{-1} \cdot \mathrm{e}^{\Phi_{\mathrm{m}} \cdot(1-\alpha)} \cdot \sum_{\mathrm{i}=1}^{\mathrm{m}-1}\left(\Psi_{\mathrm{i}} \cdot \mathrm{M}_{\mathrm{i}}\right)-\frac{\mathrm{Kchem}}{1+\mathrm{Keq}} \cdot \mathrm{e}^{(1-\alpha) \cdot \Phi_{\mathrm{m}}} \cdot \sum_{\mathrm{i}=1}^{\mathrm{m}-1}\left(\Psi_{\mathrm{i}} \cdot \mathrm{M}_{\mathrm{i}}\right)}{1+\frac{\mathrm{K}}{50} \cdot \mathrm{e}^{-\alpha \cdot \Phi_{\mathrm{m}}}+\frac{\mathrm{K} \cdot \mathrm{Keq}}{1+\mathrm{Keq}}(\mathrm{Kchem})^{-1} \cdot \mathrm{e}^{\Phi_{\mathrm{m}} \cdot(1-\alpha)} \cdot \mathrm{M}_{1}+\frac{\mathrm{Kchem}}{1+\mathrm{Keq}} \cdot \mathrm{e}^{(1-\alpha) \cdot \Phi_{\mathrm{m}}} \cdot \mathrm{M}_{1}}$

(7) is the recurrent formula for mechanism (3) (surface $E C_{r e v}$ ).

$\Psi_{\mathrm{m}}:=\frac{\frac{\mathrm{K} \cdot \mathrm{e}^{-\alpha \cdot \Phi_{\mathrm{m}}} \cdot \mathrm{Keq}}{1+\mathrm{Keq}} \cdot\left(1+\frac{1}{50} \cdot \sum_{\mathrm{j}=1}^{\mathrm{m}-1} \Psi_{\mathrm{j}}\right)+(\mathrm{Kchem})^{-1} \cdot \mathrm{K} \cdot\left(\frac{1}{1+\mathrm{Keq}}\right) \cdot \mathrm{e}^{-\alpha \cdot \Phi_{\mathrm{m}}} \cdot \sum_{\mathrm{j}=1}^{\mathrm{m}-1}\left(\Psi_{\mathrm{i}} \cdot \mathrm{S}_{\mathrm{m}-\mathrm{j}+1}\right)-\frac{\mathrm{K}}{50} \cdot \mathrm{e}^{\Phi_{\mathrm{m}} \cdot(1-\alpha)} \cdot \sum_{\mathrm{j}=1}^{\mathrm{m}-1} \Psi_{\mathrm{j}}}{\left[\left(\frac{\mathrm{K} \cdot \mathrm{e}^{-\alpha \cdot \Phi_{\mathrm{m}}} \cdot \mathrm{Keq}}{1+\mathrm{Keq}} \cdot \frac{1}{50}\right)+1\right]-(\mathrm{Kchem})^{-1} \cdot \mathrm{K} \cdot\left(\frac{1}{1+\mathrm{Keq}}\right) \cdot \mathrm{M}_{1} \cdot \mathrm{e}^{-\alpha \cdot \Phi_{\mathrm{m}}}+\frac{\mathrm{K}}{50} \cdot \mathrm{e}^{\Phi_{\mathrm{m}} \cdot(1-\alpha)}}$ 
(8) is the recurrent formula for mechanism (4) (surface $\left.C_{\text {rev }} E\right)$.

In the recurrent formulas (I-IV), the reduction current is considered to be positive and the dimensionless current is defined as $\Psi=I /\left[\left(n F S f T^{*}\right)\right]$. In the last equation, $I$ is electric current, $n$ is stoichiometric number of electrons, $S$ is active electrode surface area, $f$ is SW frequency $\left(f=1 / 2 t_{p}\right.$, where $t_{p}$ is the duration of a single potential pulse in SWV), and $\Gamma^{*}$ is the total surface concentration (i.e., the initial surface concentration of Ox species). $\Phi$ refers to the dimensionless potential ( $\Phi=\frac{n F}{R T}\left(E-E^{\phi^{\prime}}\right)$, where $E^{\phi^{\prime}}$ is the formal redox potential, $\alpha$ is the electron transfer coefficient, while other symbols have their common meaning.

The dimensionless electrode kinetic parameter $K=k_{\mathrm{s}}{ }^{\ominus} / f$ relates the formal rate constant $k_{\mathrm{s}}^{\ominus}$ to the SWV frequency. For the surface $E C_{r e v}$ and $C_{r e v} E$ mechanisms, $K_{\mathrm{chem}}=\varepsilon / f$ is the dimensionless chemical kinetic parameter, where $\varepsilon=\left(k_{\mathrm{f}}+k_{\mathrm{b}}\right)$ is the sum of the first-order rate constant $k_{\mathrm{f}}$ and $k_{\mathrm{b}}$ of the forward and backward chemical reactions, respectively. In addition, the equilibrium constant is defined as $K_{\text {eq }}=k_{\mathrm{f}} / k_{\mathrm{b}}$. For the surface $E C^{\prime}$ catalytic mechanism, the dimensionless chemical kinetic parameter is defined as $K_{\text {chem }}=k_{\mathrm{c}} / f$, where $k_{\mathrm{c}}$ is the first-order rate constant of the regenerative (catalytic) chemical reaction.

In addition, $M$ is numerical integration factor defined as $M=\exp .\left[K_{\text {chem }}(m / 50)\right]-\exp .\left[K_{\text {chem }}(m-1) / 50\right]$, where $m$ is the serial number of the time intervals. If not otherwise stated, the parameters of applied potential were SW frequency $f=$ $10 \mathrm{~Hz}, \mathrm{SW}$ amplitude $E_{\mathrm{sw}}=50 \mathrm{mV}$ and potential step $\mathrm{d} E=$ $4 \mathrm{mV}$ and starting potential of $0.3 \mathrm{~V}$. More details of the algorithms used in all models can be found in [1, 7, 17, 24, 29]. Commercially available software MATHCAD 14 was used for calculating all theoretical SW voltammograms reported in this work.

\section{Results and discussions}

Square-wave voltammetry is attributed with a unique shape of the potential modulation (see Scheme 1) that makes this technique very intriguing from several aspects.

Square-wave amplitude $E_{\mathrm{sw}}$ (see Scheme 1 ) is actually the height of the potential pulse, i.e., a potential jump up and down (from several millivolts to hundred millivolts) at every single step of the underlying staircase potential. Consequently, SWV enables inspection of both oxidation and reduction processes at every single potential of the staircase ramp. The overall voltammetric response consists of three current components, i.e. forward $\left(I_{f}\right)$, backward $\left(I_{b}\right)$ and differential net component $\left(I_{n e t}=I_{f}-I_{b}\right)$. The latter enables inspecting independently three current components as a function of relevant parameters of a certain electrochemical experiment. The

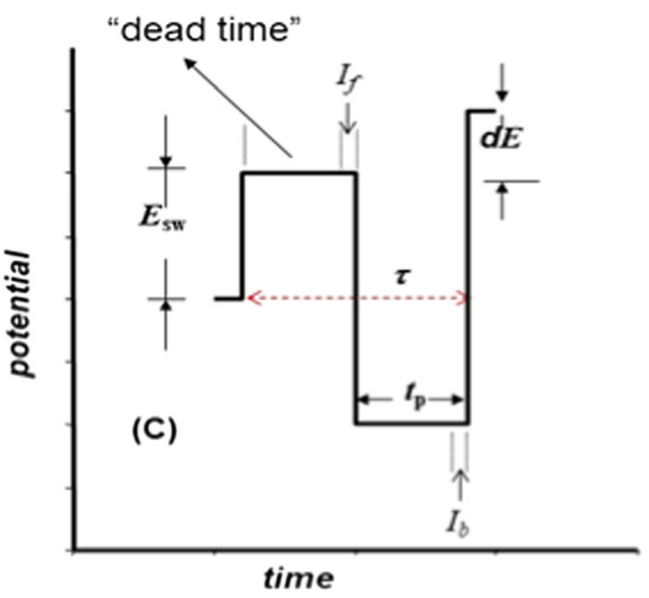

Scheme 1 Schematic representation of a potential cycle in SWV consisting of two adjacent oppositely oriented potential pulses. The current is measured at the end of potential pulses (in the sectors assigned with " $I_{\mathrm{f}}$ " and " $I_{\mathrm{b}}$ "). In the so-called dead time, the current is not measured, but the electrode reactions go on also in this time segment

current measuring in SWV takes place in a narrow time segment at the end of each potential pulse $\left(I_{f}\right.$ and $I_{b}$ in the Scheme 1). In this way, one discriminates significantly faradaic from the charging current. Of course, the surface concentration variation of redox species prior to the current sampling in the socalled dead time (see scheme 1) plays an important role in overall features of SW voltammograms [25, 26]. Before we start elaborating some relevant characteristics of surface electrode processes coupled with chemical reactions, we shortly recall to the most important features of the simple surface mechanism (1), considered as a referent system in the context of the current study.

\section{Simple surface confined electrode mechanism}

Shown in Fig. 1 is a series of theoretical square-wave voltammograms of a simple surface reaction, simulated for several values of the dimensionless electrode kinetic parameter $K$. As the rate of the electrode reaction increases, one observes significant enlargement of all current components. Beyond the maximum peak current reached for $K \approx 0.5$ (Fig. 1b), one observes a considerable current decrease by further increasing of $K$ (Fig. 1c-f). At the same time, cathodic (forward) peak starts to shift towards more positive potential values, while anodic (backward) peak shifts in opposite direction. As a consequence, splitting of the net SWV peak appears (Fig. 1d). The potential separation between the split net peaks increases in proportion to $K$ (Figs.1d-f and 2b).

Shown in Fig. 2a is the relationship of net peak current as a function of $\log (K)$, simulated for three different values of the SW amplitude. These so-called quasi-reversible maxima imply that the maximal net peak current is a function of the electrode reaction rate (via $K$ ), as well as the SW amplitude. 
Fig. 1 Simple surface redox reaction: Effect of the dimensionless electrode kinetic parameter $K$ to the features of calculated square-wave voltammograms. The simulation parameters were SW frequency $f=$ $10 \mathrm{~Hz}, \mathrm{SW}$ amplitude $E_{\mathrm{sw}}=$ $50 \mathrm{mV}$, potential step $\mathrm{d} E=4 \mathrm{mV}$, temperature $T=298 \mathrm{~K}$. In all simulations, the value of electron transfer coefficient was $\alpha=0.5$, while the number of electron exchanged was $n=2$. The values of $K$ are given in the charts. In all simulated voltammograms in this work, the reduction (forward) current is assigned with blue line, the oxidation (backward) current is assigned with red line, while the black line represents the "net" current
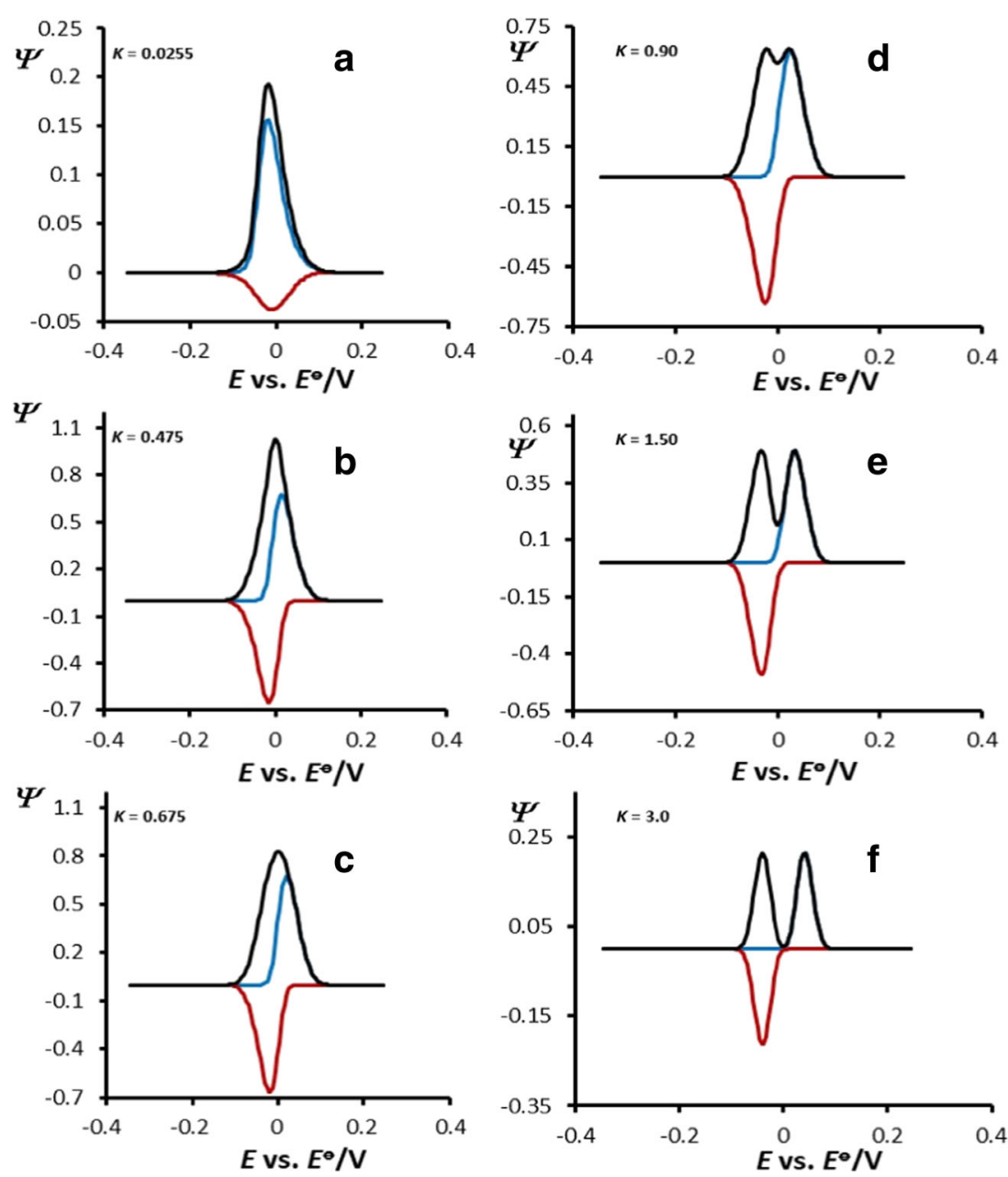

This is to be expected, since the kinetics of the electrode reaction depends not only on the formal rate constant of the electron transfer (and on temperature) but also on the potential applied, which is determined by the staircase potential and the pulse applied (i.e., SW amplitude).

The phenomenon of quasi-reversible maximum emerges when the rate of electron transfer and the duration of the potential pulses in SWV are synchronized [1, 6-10].

On the other hand, the splitting of the net peak is attributed to electrode processes with rather fast electron transfer kinetics $[1,7,8,17]$. When the electron transfer rate is large, the time required for redox transformation of Ox(ads) to Red(ads) at the potential of a given pulse becomes very short. Hence, when the pulse duration is longer than the time needed to achieve the redox transformation of $\mathrm{Ox}(\mathrm{ads})$ to $\mathrm{Red}(\mathrm{ads})$, the measured current at the end of the pulse is very small, resulting in a minute overall voltammetric response (Fig. 1e, f). Both "quasi-reversible maximum" and "net SWV peak splitting" can be explored to get an access to the formal rate constant value of a studied system in a very elegant way. A detailed overview of the corresponding methods can be found elsewhere [1, 6-10, 17]. In [27, 28, 30-39], one can find a detailed description how to alternatively evaluate $k_{\mathrm{s}}{ }^{\ominus}$ and the electron transfer coefficient $\alpha$.

\section{Surface confined catalytic (regenerative) electrode mechanism (surface EC'):}

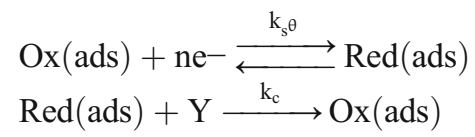

In the family of surface electrode processes coupled with chemical reactions, the simplest case is probably the surface catalytic mechanism (surface $\mathrm{EC}^{\prime}$ ) (2). Here, an irreversible chemical redox reaction between electrochemically generated product Red(ads) with a given reactant $\mathrm{Y}$ (present in a large excess in the voltammetric cell) leads to regeneration of the initial reactant $\mathrm{Ox}(\mathrm{ads})$. Shown in Fig. 3 are SW voltammograms simulated for moderate rate of electrode reaction $(K=$ 0.5 ) and several values of the catalytic (chemical) parameter $K_{\text {chem }}$. An increase of the reduction (forward) and a decrease of the oxidation (backward) current branch with increasing of 


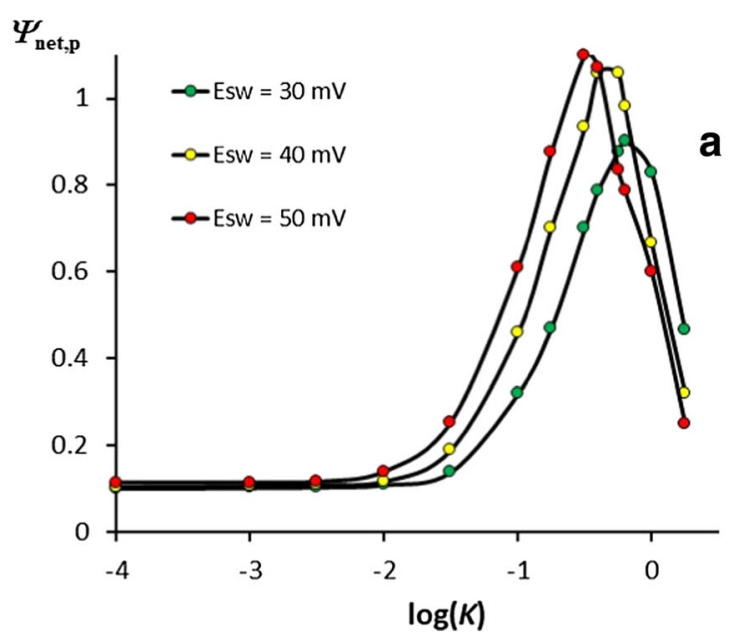

$\Delta E_{\mathrm{p}} / \mathrm{mV}$

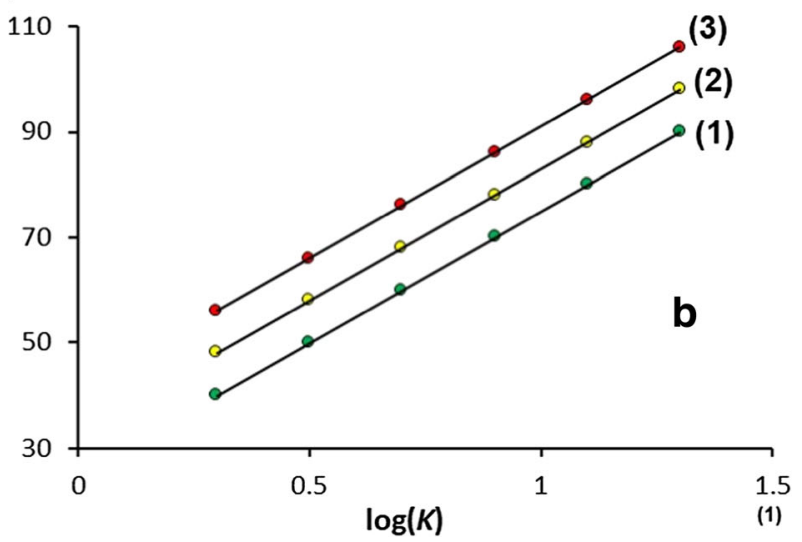

Fig. 2 Simple surface redox reaction. a Quasi-reversible maxima of simple surface redox reactions simulated for three different values of SW amplitude. b Dependence of the potential separation of "split net SWV peaks" as a function of $\log (K)$, simulated for square-wave amplitudes of $30 \mathrm{mV}(1), 40 \mathrm{mV}(2)$ and $50 \mathrm{mV}$ (3). All other simulation parameters are same as those in Fig. 1

$K_{\text {chem }}$ is a typical feature for this mechanism. In parallel, the phenomenon is accompanied by an increase of the net peak current. As the catalytic parameter $K_{\text {chem }}$ gets larger, both reduction and oxidation current gain identical sign and approach to each other with their magnitudes. It happens when the rate of the catalytic reaction is much higher than the rate of the redox transformation at the working electrode surface. As a consequence, a multiple reuse of the starting electroactive material occurs in the time-measuring segment of each potential pulse, which produces current in proportion to $K_{\text {chem }}$. Contrary to cyclic voltammetry, where one observes a steady-state sigmoid-shaped cyclic voltammograms for large rates of the regenerative reaction $[2,3,20,40,41]$, in SWV, one finds a well-defined net SW peak for any value of the catalytic parameter $K_{\text {chem }}$ (Fig. 3c, d). This effect is a consequence of the differential nature of the net SW component. In addition, it stems from the features of the forward and backward current components, which are always separated to some
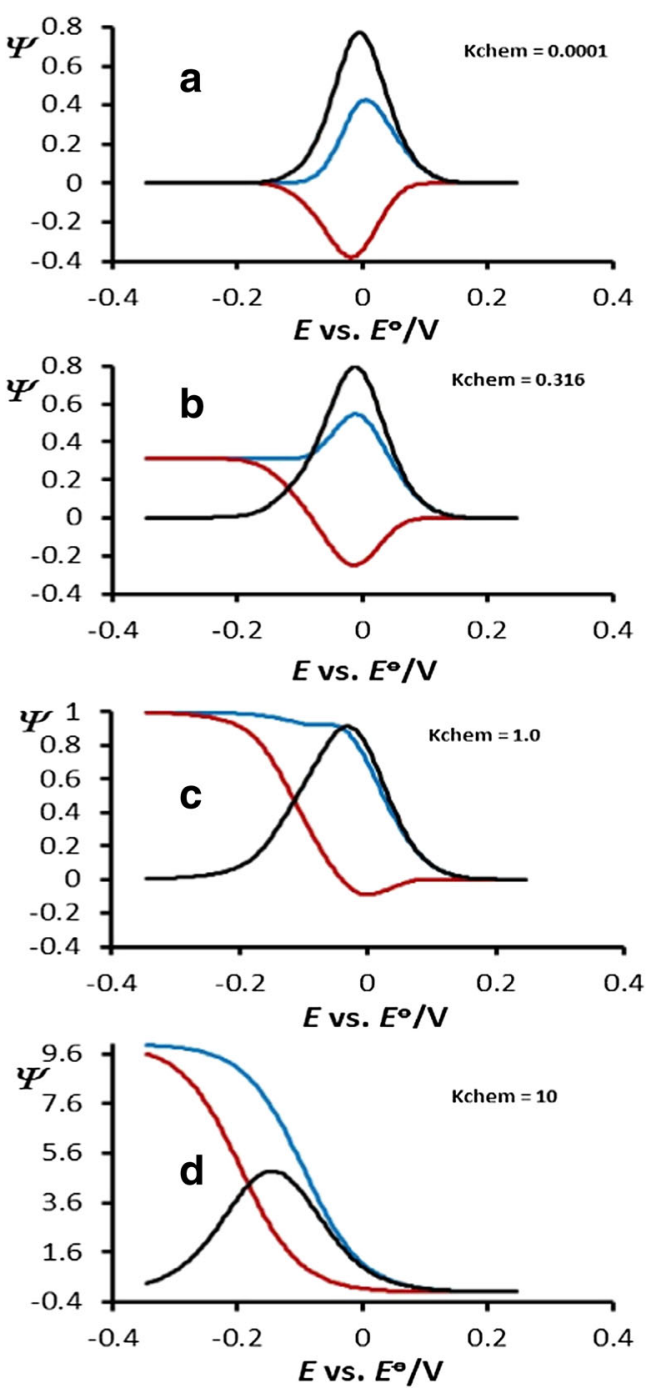

Fig. 3 Surface $E C^{\prime}$ catalytic mechanism: case with moderate electron transfer rate: Effect of the chemical (catalytic) parameter $K_{\text {chem }}$ to the features of calculated SW voltammograms. The values of the catalytic parameter $K_{\text {chem }}$ were 0.0001 (a), 0.316 (b), 1 (c) and $10(\mathbf{d})$. The value of the dimensionless electrode kinetic parameter $K$ was 0.5 . All other simulation parameters were same as those in Fig. 1

extent at the potential axis, if SW amplitudes larger than $10 \mathrm{mV}$ are applied [22].

For $K_{\text {chem }}>1$, a regular shift of the net SWV peak potentials in a negative direction is detected (Fig. 3d). Indeed, this is because more energy is needed to reduce the new influx of Ox(ads) species resupplied via chemical redox reaction of Red(ads) with Y. This is clearly presented in Fig. 4a, where only the net SWV peaks are shown, simulated for several high values of the catalytic parameter $K_{\text {chem. }}$ In Fig. $4 \mathrm{~b}$, the forward and backward current components of the corresponding net voltammograms of Fig. 4a are presented. Obviously, both components gain a sigmoid shape as typical for steady-state processes. However, both currents do not merge to each other, as in cyclic voltammetry [2, 40,41], even for large values of the chemical parameter $K_{\mathrm{chem}}$. The reason for this behaviour is 

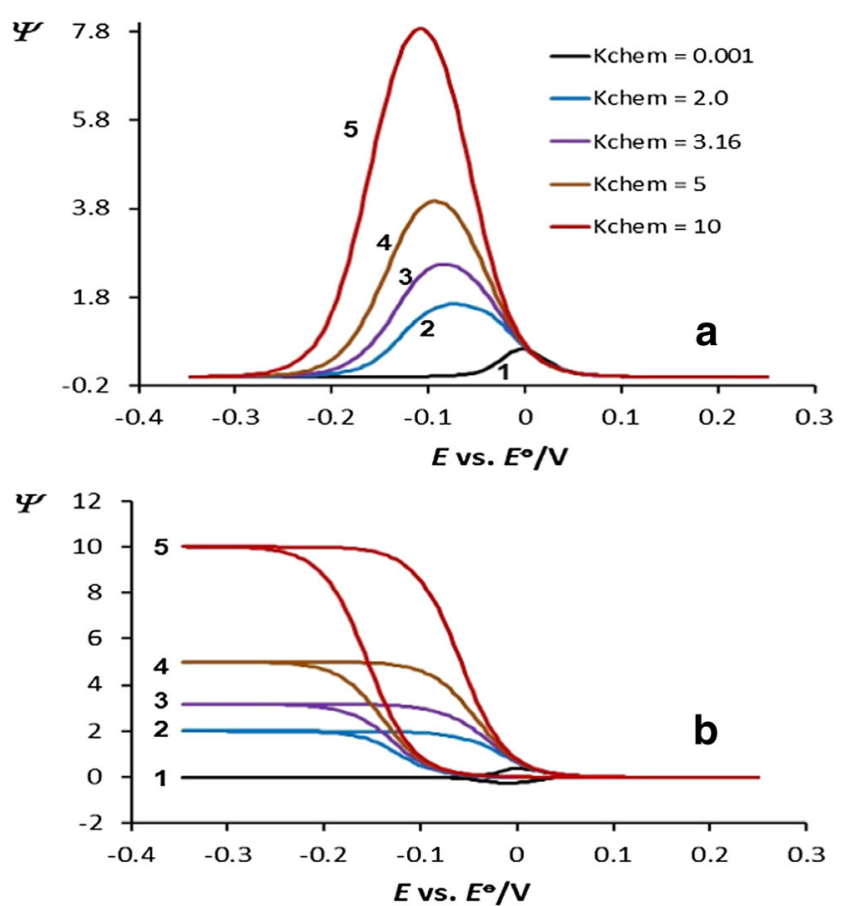

Fig. 4 Surface EC' catalytic mechanism: case with moderate electron transfer rate: Effect of the chemical (catalytic) parameter $K_{\text {chem }}$ to the features of calculated net SW voltammograms (a) and to the corresponding reduction and oxidation SW currents (b). In both cases, the values of the catalytic parameter $K_{\text {chem }}$ were 0.001 (1), 2.0 (2), 3.16 (3), 5.0 (4) and 10 (5). b The value of the dimensionless electrode kinetic parameter $K$ was 0.10 . All other simulation parameters were same as in Fig. 1

in the influence of applied square-wave amplitude applied, as it is explained in more details in [22].

If the electrode reaction is very fast, then the splitting of the net SWV peak occurs (Fig. 5a). Increasing the rate of the catalytic reaction leads to a decrease of the backward (oxidation) current component and corresponding increase of the forward (reduction) current (Fig. 5b, c). Eventually, for $K_{\text {chem }}>0.02$, the splitting vanishes and a single net peak is observed (Fig. 5d). This is a unique feature, which can serve as a criterion for qualitative characterization of this mechanism $[18,20]$.

In [22], we demonstrated that in the region of moderate-tolarge rate of the regenerative reaction (roughly $-1.5<$ $\left.\log \left(K_{\text {chem }}\right)<1.5\right)$, the net peak potential $E_{\text {net,p }}$ is a linear function of $\log \left(K_{\text {chem }}\right)$ (Fig. 6a).

While the slope of the line $E_{\mathrm{p}} \mathrm{vs} \cdot \log \left(K_{\mathrm{chem}}\right)$ is $-59 \mathrm{mV}$, the intercept is defined as follows: intercept $=E_{\text {Ox(ads) } / \operatorname{Red}(a d s)}^{\ominus}+$ $2.303 R T(\alpha n F)^{-1} \log (K)$. If the value of electron transfer coefficient $\boldsymbol{\alpha}$ is previously known $[1,30]$, the latter equation allows estimation of the electrode kinetic parameter $K$ (hence the formal rate constant $k_{\mathrm{s}}{ }^{\ominus}$, since $K=k_{\mathrm{s}}{ }^{\ominus} / \mathrm{f}$ ) by varying the concentration of the regenerative agent $Y$. This comes from the fact that the dimensionless chemical parameter is defined as $K_{\text {chem }}=k_{\mathrm{c}} / f$, where $k_{\mathrm{c}}=k_{\mathrm{c}}{ }^{\prime} c(\mathrm{Y})$ and $k_{\mathrm{c}}{ }^{\prime}$ is the real second-
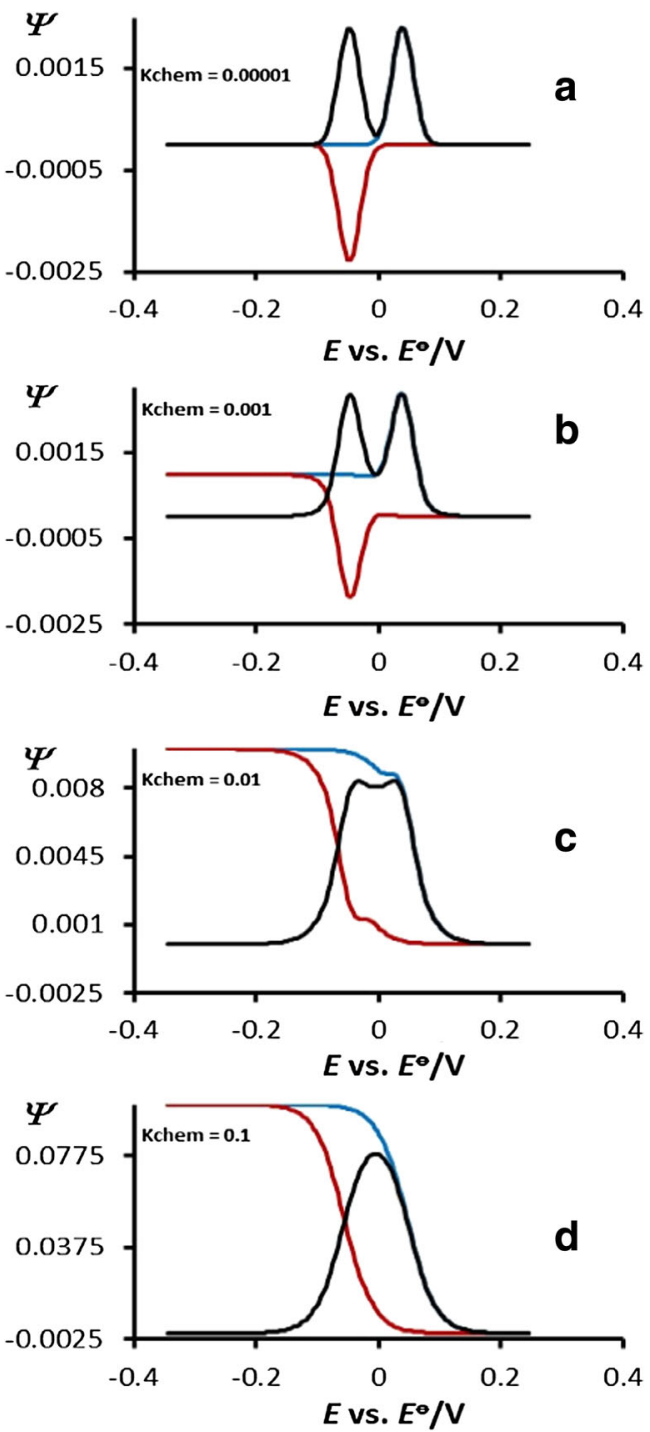

Fig. 5 Surface $E C^{\prime}$ catalytic mechanism: case with fast electron transfer rate: Effect of the chemical (catalytic) parameter $K_{\text {chem }}$ to the features of calculated SW voltammograms. The values of the catalytic parameter $K_{\text {chem }}$ were 0.00001 (a), 0.001 (b), 0.01 (c) and 0.1 (d). The value of the dimensionless electrode kinetic parameter $K$ was 10 . All other simulation parameters were same as those in Fig. 1

order rate constant of the regenerative reaction. Thus, the rate of the surface electrode reaction can be estimated in a timeindependent experiment, i.e. at constant SW frequency.

Furthermore, from the limiting current of the steady-state forward and backward currents (Fig. 4b), the rate of the regenerative chemical reaction can be estimated in a simple way. Shown in Fig. $6 \mathrm{~b}$ is the dependence of the limiting current of both components as a function of the chemical parameter $K_{\text {chem }}$. The slope of the linear function allows determination of $k_{\mathrm{c}}{ }^{\prime}$ only by altering the concentration of regenerative agent taking into account that $K_{\text {chem }}=k_{\mathrm{c}}{ }^{\prime} c(\mathrm{Y})$.

Considering features of SW voltammograms presented in Figs. 4 and 5, and the dependences presented in Fig. 6, it follows that the kinetics of both electrode and chemical 

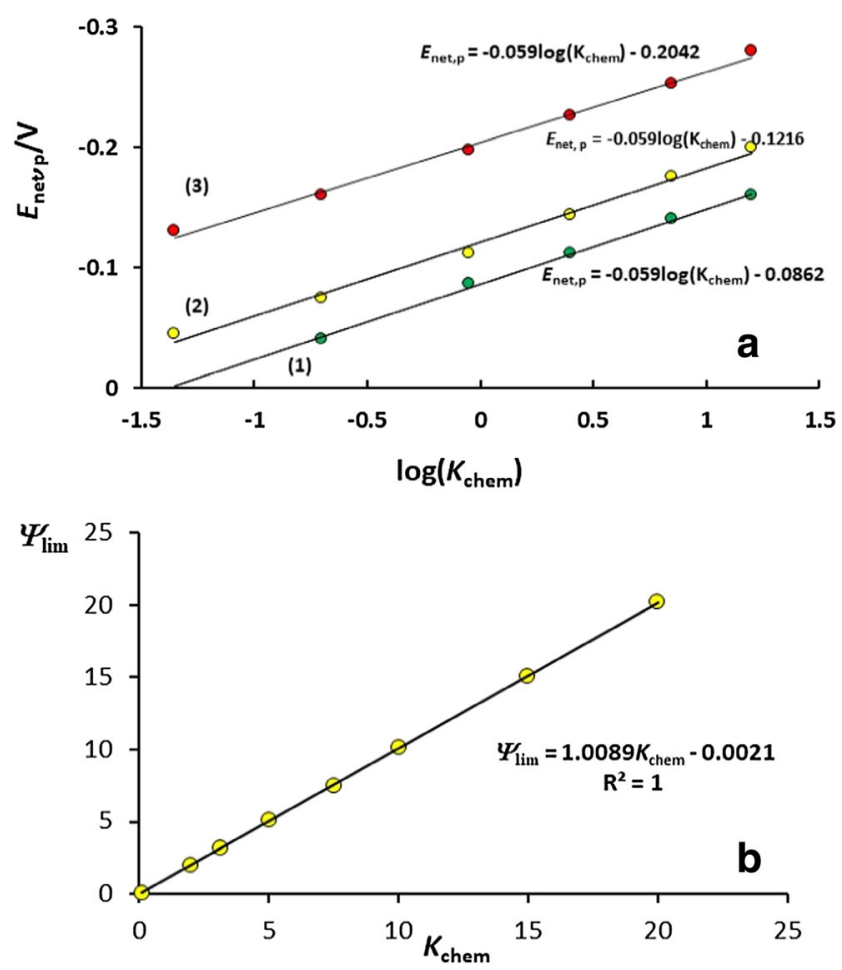

Fig. 6 Surface $E C^{\prime}$ catalytic mechanism: case with slow and moderate electron transfer rate. a Dependence of the net SWV peak potentials as a function of $\operatorname{logarithm}$ of catalytic parameter $\log \left(K_{\text {chem }}\right)$. The curves are simulated for three values of dimensionless electrode kinetic parameter, i.e. $\log (K)$ of $-0.40(1),-1.0$ (2) and -2.0 (3). b Dependence of the limiting currents of SW voltammograms (measured at potentials of $0.30 \mathrm{~V}$ ) from Fig. $4 \mathrm{~b}$ as a function of catalytic parameter $K_{\text {chem }}$, simulated for $K$ of 0.10. All other simulation parameters were same as those in Fig. 1

reaction is accessible in a time-independent experiment. Thus, it can be achieved at constant scan rate and frequency of the SW voltammetric experiment, taking advantage of altering the concentration of regenerative agent $\mathrm{Y}$ only.

\section{Surface-confined electrode reaction coupled with a follow-up reversible chemical reaction (surface $\mathrm{EC}_{\text {rev }}$ )}

Ox(ads $)+$ ne$^{-}-\underset{\mathrm{k}_{\mathrm{f}}}{\stackrel{\mathrm{k}_{\mathrm{s}} \theta}{\rightleftarrows}} \operatorname{Red}($ ads $)$
$\operatorname{Red}($ ads $)+\mathrm{Y} \underset{\mathrm{k}_{\mathrm{b}}}{\stackrel{\rightleftarrows}{\rightleftarrows}} \mathrm{Z}(\mathrm{ads})$

The surface $E C_{r e v}$ mechanism is often encountered in the voltammetry of various immobilized enzymatic reactions, as well as with many lipophilic drugs prone to adsorb at the electrode surface $[1,6,7,10-17,40-49]$. We consider here a surface confined electrode reaction in which the electrochemically generated redox product is involved in a reversible follow-up chemical reaction [26]. The analysis is focused mainly on the $E C_{r e v}$ mechanism featuring fast electron transfer.
Voltammetric features are mainly affected by the electrode kinetic parameter $K=k_{\mathrm{s}}{ }^{\ominus} / f$, as in previous mechanisms, as well as by the equilibrium constant of the chemical step $K_{\mathrm{eq}}=k_{\mathrm{f}} / k_{\mathrm{b}}$ and the overall rate of the follow-up chemical reaction via the dimensionless chemical kinetic parameter $K_{\text {chem }}=\left(k_{\mathrm{f}}+k_{\mathrm{b}}\right) / f$. As the equilibrium constant determines the equilibrium amount of Red(ads) species, the chemical parameter $K_{\text {chem }}$ represents the rate of removal/resupply of Red(ads) species in the time frame of each potential pulse.

As it has been shown in our recent work [26], for a given value of $K$ and $K_{\text {chem }}$, voltammetric response is strongly affected by the equilibrium constant (see Fig. 6 in [26] for example). Remarkable voltammetric features emerge for fast electrode reaction. For instance, for $K_{\mathrm{eq}}>$ 1 , the splitting of the net SW peak is strongly affected by the kinetics of the follow-up chemical step. Shown in Fig. 7 are voltammograms illustrating the effect of $K_{\text {chem }}$ in the case of split net SWV peak. It is important to notice that within a broad region of $K_{\text {chem }}$ values $\left(0.001<K_{\text {chem }}\right.$ $<0.5$ ), simultaneous increase of both reduction (forward) and oxidation (backward) current components is encountered. Interestingly, the backward (oxidation) peak current rises more rapidly by increasing $K_{\text {chem }}$. At the same time, the peak potential of the backward component shifts towards more positive values as $K_{\text {chem }}$ increases. In such scenario, the splitting of the net SW voltammogram vanishes for $K_{\text {chem }}$ of 0.04 . In addition, both reduction and oxidation peaks further increase in proportion to $K_{\text {chem }}$ within the interval $0.04<K_{\text {chem }}<0.5$. Eventually, for $K_{\text {chem }}>0.6$, both current components commence decreasing, acquiring typical shape for $E C_{r e v}$ mechanism [1-3, $26]$. Hence, for moderate and high values of $K_{\text {eq }}$, the overall rate of the chemical step influences significantly the electrode reaction. This is also shown in Fig. 8a, where a series of quasi-reversible maxima are presented, simulated for $K_{\text {eq }}=10$ and several values of $K_{\text {chem }}$. As the values of the chemical parameter $K_{\text {chem }}$ increase from 0.0075 to 0.075 , the position of maximum shifts from $\log \left(K_{\max }\right)=$ -0.775 to $\log \left(K_{\max }\right)=1$. At the same time, the increasing rate of the follow-up chemical step causes the overall currents to increase, as shown in Fig. 8a. The linear dependence of $\log \left(K_{\text {chem }}\right)$ vs. $\log \left(K_{\text {max }}\right)$ (Fig. 8 b) allows determination of the value of $K_{\text {chem }}$ in a very elegant way as described in [26].

As we have shown in our recent works $[25,26,37$, 39], the observed phenomena in Figs. 7 and 8 arise mainly from the specific chronoamperometric features of this electrode mechanism in SWV. If the rate of electron transfer is comparable to the overall rate of the chemical reaction, simultaneous increase of both forward and backward current components is observed. Similar effect was initially observed in the case of adsorption- 

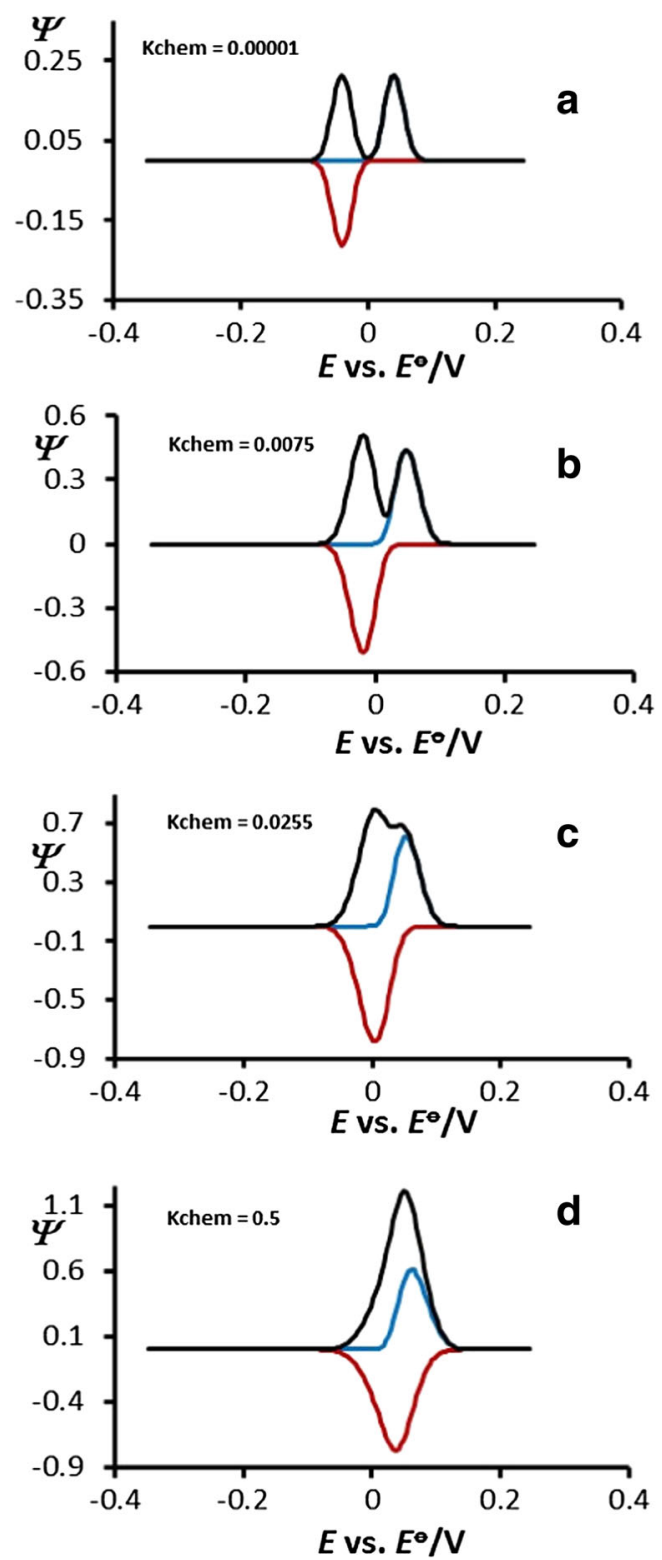

Fig. 7 Surface ECrev mechanism: case with fast electrode transfer rate: Effect of the dimensionless chemical parameter $K_{\text {chem }}$ to the features of simulated SW voltammograms simulated for a value of the dimensionless electrode kinetic parameter $K=3.0$. The equilibrium constant of the follow up chemical reaction was set to $K$ eq $=10$, while the value of dimensionless chemical rate parameter $K_{\text {chem }}$ was 0.00001 (a), 0.0075 (b), 0.0255 (c) and 0.5 (d). All other simulation parameters were same as those in Fig. 1

complicated $E C_{\text {irev }}$ mechanism [42, 43, 48]. Pivotal role in such scenario is attributed to the rate of chemical removal of redox active form Red(ads), causing the electrode reaction to proceed further and the end of potential pulse, thus producing a larger current. The features described in Figs. 7 and 8 are encountered with the surface $E C_{\text {rev }}$ mechanism only, and they can be used as diagnostic criteria for qualitative and kinetic characterization as elaborated in detail in [26].
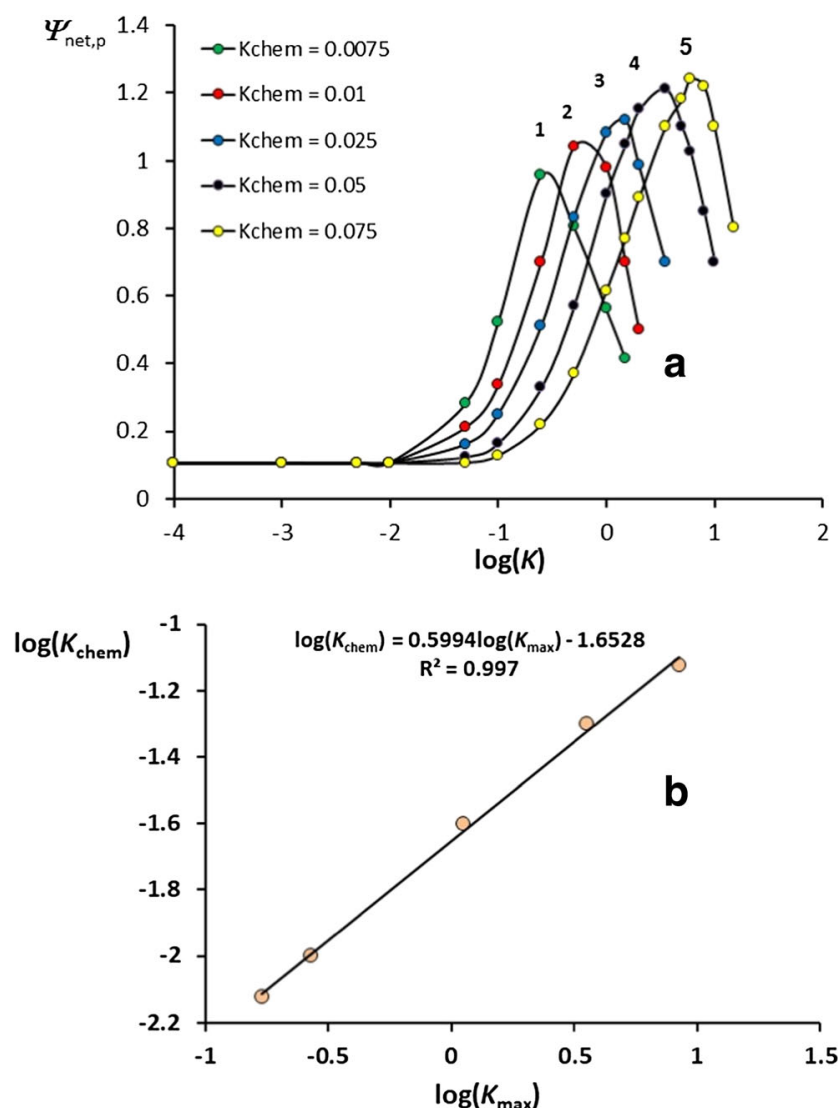

Fig. 8 Surface ECrev mechanism. a Quasi-reversible maxima simulated for $K$ eq $=10$ and for several values of dimensionless chemical rate parameter $K_{\text {chem. }}$. b Dependence between the logarithm of the chemical rate parameter $\log \left(K_{\text {chem }}\right)$ and the logarithm of maximal values of the dimensionless electrode kinetic parameters $\log \left(K_{\max }\right)$ from Fig. 8a. All other simulation parameters were same as those in Fig. 1

\section{Surface confined electrode reaction coupled with a preceding reversible chemical reaction (surface $C_{\text {rev }}$ )}

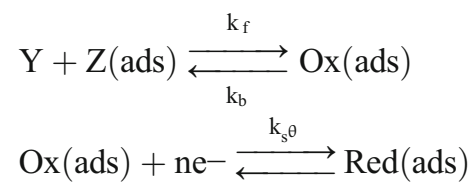

From all surface redox mechanisms complicated with chemical reactions, the electrode reaction coupled with a preceding chemical step $\left(C_{r e v} E\right.$ mechanism) is, indeed, the most complex one. As the initially available material at the working electrode surface depends on the value of the equilibrium constant $K_{\mathrm{eq}}$, the resupply/removal of $\mathrm{Ox}(\mathrm{ads})$ species during the time frame of the experiment is dictated by the chemical rate parameter $K_{\text {chem }}$. An interplay between the specific chronoamperometric characteristics of the surface electrode reaction and the chemical step results in a complex voltammetric outcome of 
the experiment [19]. Here, as in the previous case, we focus mainly to voltammetry typical for fast electrode reaction.

Shown in Fig. 9 are theoretical voltammograms of a quasireversible electrode reaction, simulated for $K_{\text {eq }}=1$ and three different values of the chemical rate parameter $K_{\text {chem }}$. Obviously, an increase of $K_{\text {chem }}$ from 0.01 to 3.16 leads to a simultaneous increase of the overall voltammetric response. Indeed, the effect of the overall chemical kinetics depends strongly on the value of $K_{\text {eq }}$, as shown in Fig. 10, and the overall effect is very complex. The rate of the preceding chemical reaction, represented by the parameter $K_{\text {chem }}$, influences the intensity, position and the shape of all current components.
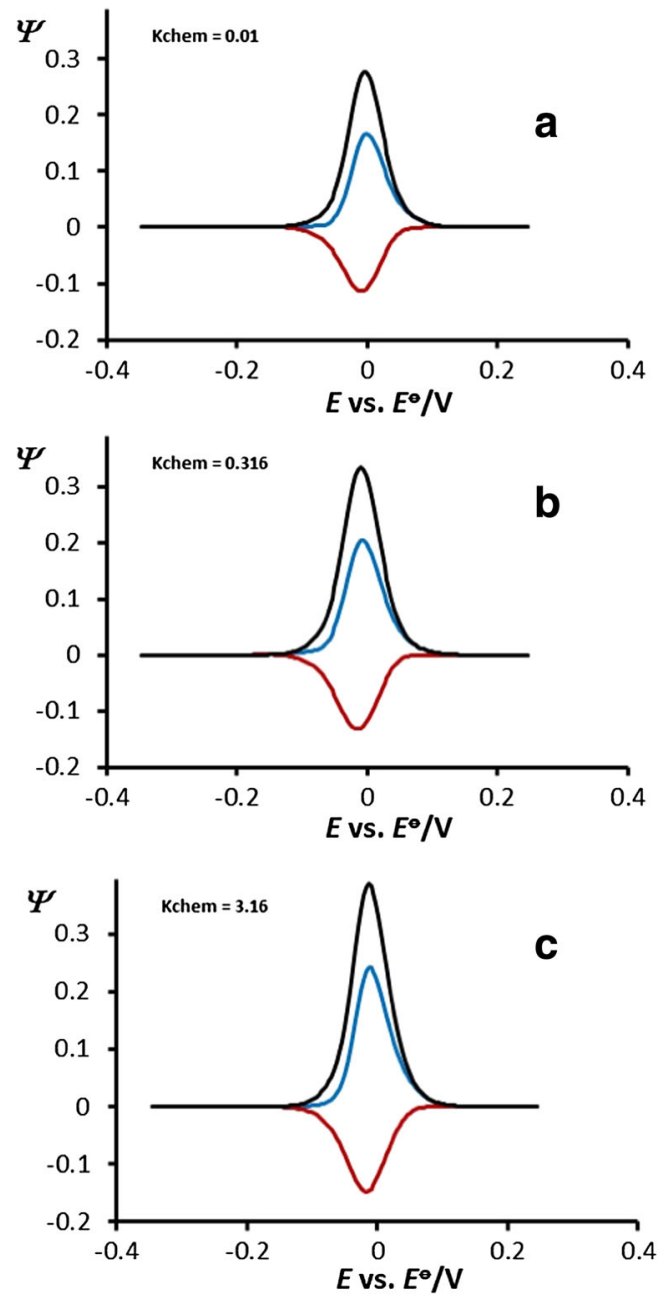

Fig. 9 Surface CrevE mechanism: case with moderate electron transfer rate: Effect of the dimensionless chemical parameter $K_{\text {chem }}$ to the features of the SW voltammograms simulated for a value of the dimensionless electrode kinetic parameter $K=1.0$, and for equilibrium constant of preceding chemical reaction $K$ eq $=1$. The values of the dimensionless chemical rate parameter $K_{\text {chem }}$ were 0.01 (a), 0.316 (b) and 3.16 (c). All other simulation parameters are same as those in Fig. 1
The effect of $K_{\text {chem }}$ is more pronounced when the electrode reaction is fast. Shown in Figs. 11 and 12 are SW voltammograms when the net peak splitting occurs, calculated for $K_{\text {eq }}=1$ and $K_{\text {eq }}=0.01$, respectively. Although, at a first glance the situation might look similar, the voltammetric behaviour presented in Figs. 11 and 12 is significantly different. For $K_{\text {eq }}=1$, the overall rate of the preceding chemical reaction $\left(K_{\text {chem }} \leq 0.05\right)$ has mainly an influence to the peak current of the forward (reduction) component (Fig. $11 \mathrm{a}-\mathrm{c}$ ). However, the rate of the preceding reaction has a remarkable effect to the morphology of both forward and backward current components, in particular at more negative potentials than the peak potentials (see Fig. 11b, c).

Specifically, the current in post-peak potential region of both current components is significantly elevated, the phenomenon being proportional to the rate of the preceding reaction. Such phenomena can be ascribed to the effect of additional resupply of $\mathrm{Ox}(\mathrm{ads})$ species by the preceding chemical reaction during the time frame of the voltammetric experiment.
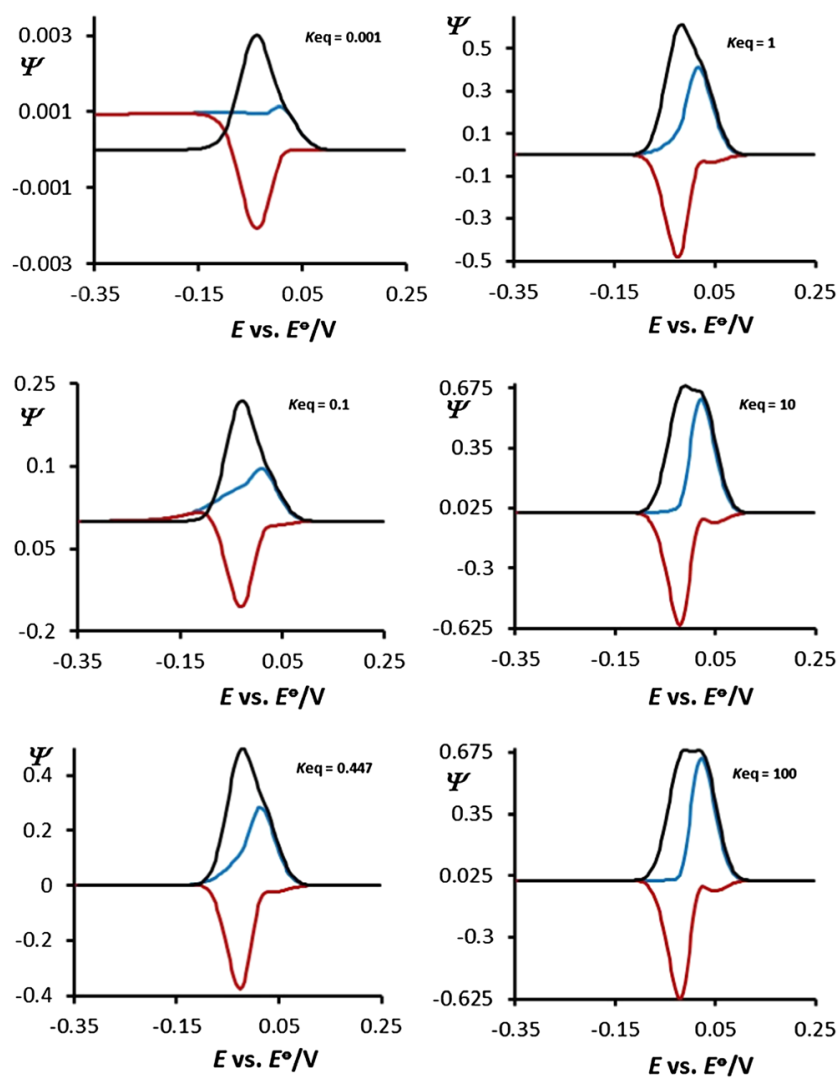

Fig. 10 Surface CrevE mechanism: case with moderate electron transfer rate: Theoretical SW voltammograms simulated for a value of the dimensionless electrode kinetic parameter $K=0.794, K_{\text {chem }}$ of 1.0 , and for several equilibrium constants of preceding chemical reaction. The values of equilibrium constants $K$ eq are given in the charts 
Fig. 11 Surface CrevE mechanism: case with fast electron transfer rate: Effect of the dimensionless chemical parameter $K_{\text {chem }}$ to the features of the SW voltammograms simulated for a value of the dimensionless electrode kinetic parameter $K=10$, and for an equilibrium constant of preceding chemical reaction $\mathbf{K e q}=\mathbf{1}$. The values of the dimensionless chemical rate parameter $K_{\text {chem }}$ were 0.00001 (a), 0.00316 (b), $0.0316(\mathbf{c}), 3.16(\mathbf{d}), 31.6(\mathbf{e})$ and 316 (f). All other simulation parameters are same as in Fig. 1
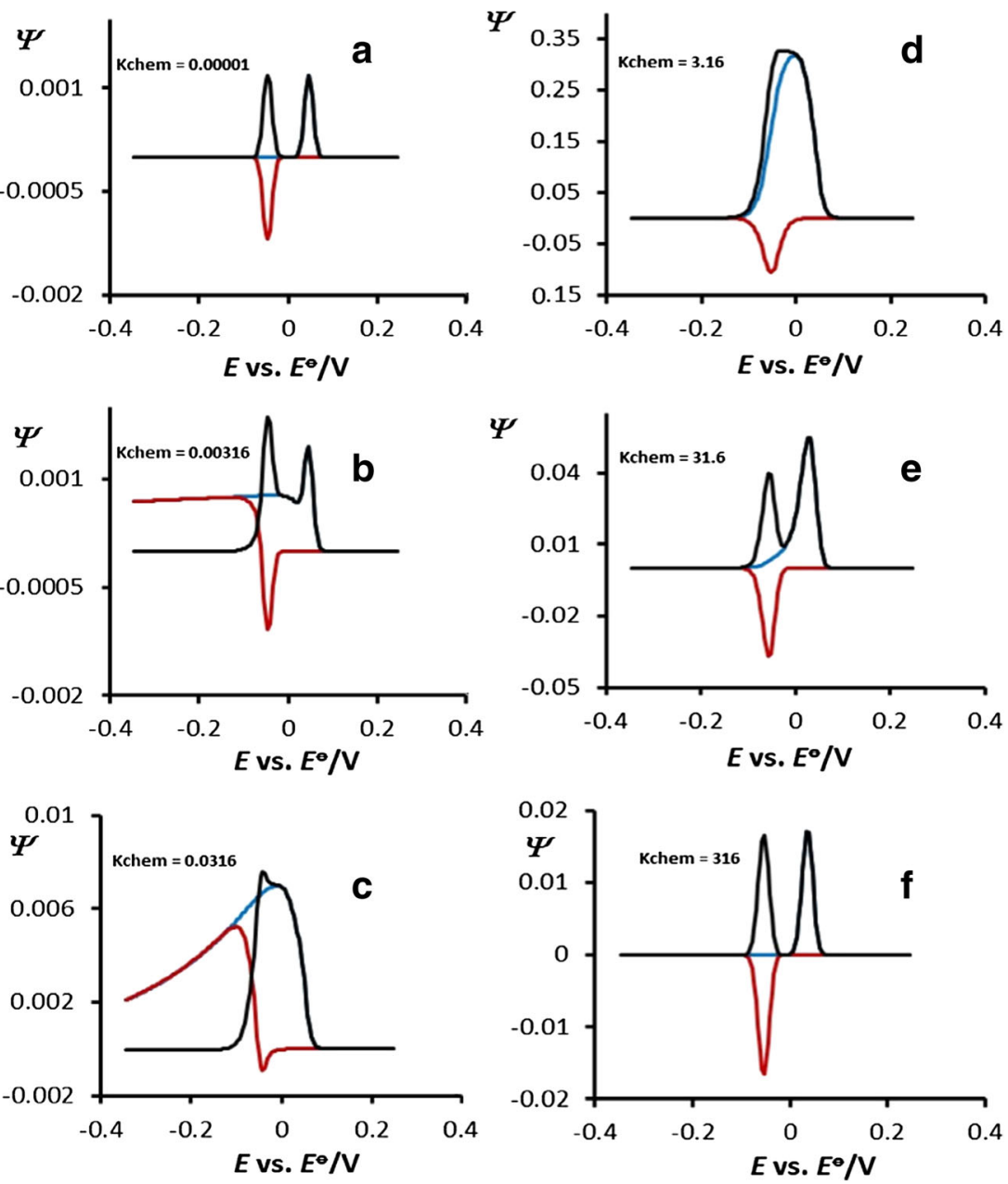

The net SWV peak splitting vanishes in the range 0.05 $<K_{\text {chem }}<10$ (Fig. 11c, d). Further increase of $K_{\text {chem }}>10$ leads to simultaneous increase of both reduction and oxidation peak currents, while the splitting of net SWV peaks is re-established (see Fig. 11e, f). The voltammetric behaviour of a fast surface electrode reaction preceded by a chemical reaction described in Fig. 11 is unique for this mechanism and can serve as qualitative criteria for characterization of the mechanism.

Furthermore, when the preceding chemical reaction is thermodynamically unfavourable, attributed with $K_{\text {eq }}=0.01$ (Fig. 12), an initial increase of $K_{\text {chem }}$ from 0.001 to 0.5 leads to disproportional increase of forward and backward current components. Unexpectedly, the oxidation (backward) peak current gains more in the intensity than the reduction one (Fig. $12 \mathrm{~b}, \mathrm{c}$ ). For $K_{\text {chem }}>2$, the splitting disappears (Fig. 12d), while further increase of $K_{\text {chem }}$ up to 500 causes both current components to gain in the intensity almost identically. For $K_{\mathrm{eq}}=0.01$, the net SWV peak splitting is lost and cannot be re-established by further increase of $K_{\text {chem }}$, contrary to the case observed for higher $K_{\mathrm{eq}}$ values (compare
Figs. 11e, f and 12e, f, for example). Accordingly, the differences of the voltammetric behaviour illustrated in Figs. 11 and 12 can serve as qualitative criteria for rough assessment of the equilibrium constant.

Although the evolution of the voltammetric pattern presented in Fig. 12 resembles the surface $E C_{r e v}$ mechanism illustrated in Fig. 7, yet the two cases differ significantly. While the phenomenon of post-peak elevated current for both forward and backward current components is typical for the surface $C_{r e v} E$ mechanism (due to the resupply of an electroactive material), it does not appear in the case of $E C_{r e v}$ mechanism (compare Fig. 12b-d with Fig. 7, for example). The surface $C_{r e v} E$ mechanism differs from the surface $E C_{r e v}$ mechanism in, at least, one more relevant aspect. While for the surface $E C_{\text {rev }}$ mechanism, the position of quasi-reversible maximum is a function of $K_{\text {chem }}$ (see Fig. 8a), the position of the maximum does not depend on $K_{\text {chem }}$ in the case of surface $C_{r e v} E$ mechanism [19].

Shown in Fig. 13a is the dependence of the peak current ratio of the absolute values of the forward and backward components as a function of $\log \left(K_{\text {chem }}\right)$, estimated for several 
Fig. 12 Surface CrevE mechanism: case with fast electron transfer rate: Effect of the dimensionless chemical parameter $K_{\text {chem }}$ to the features of the SW voltammograms simulated for a value of the dimensionless electrode kinetic parameter $K=1.778$, and for an equilibrium constant of preceding chemical reaction $\mathbf{K e q}=\mathbf{0 . 0 1}$.

The values of the dimensionless chemical rate parameter $K_{\text {chem }}$ were $0.001(\mathbf{a}), 0.056(\mathbf{b}), 0.316$ (c), $5.62(\mathbf{d}), 56.2(\mathbf{e})$ and $562(\mathbf{f})$. All other simulation parameters are same as in Fig. 1
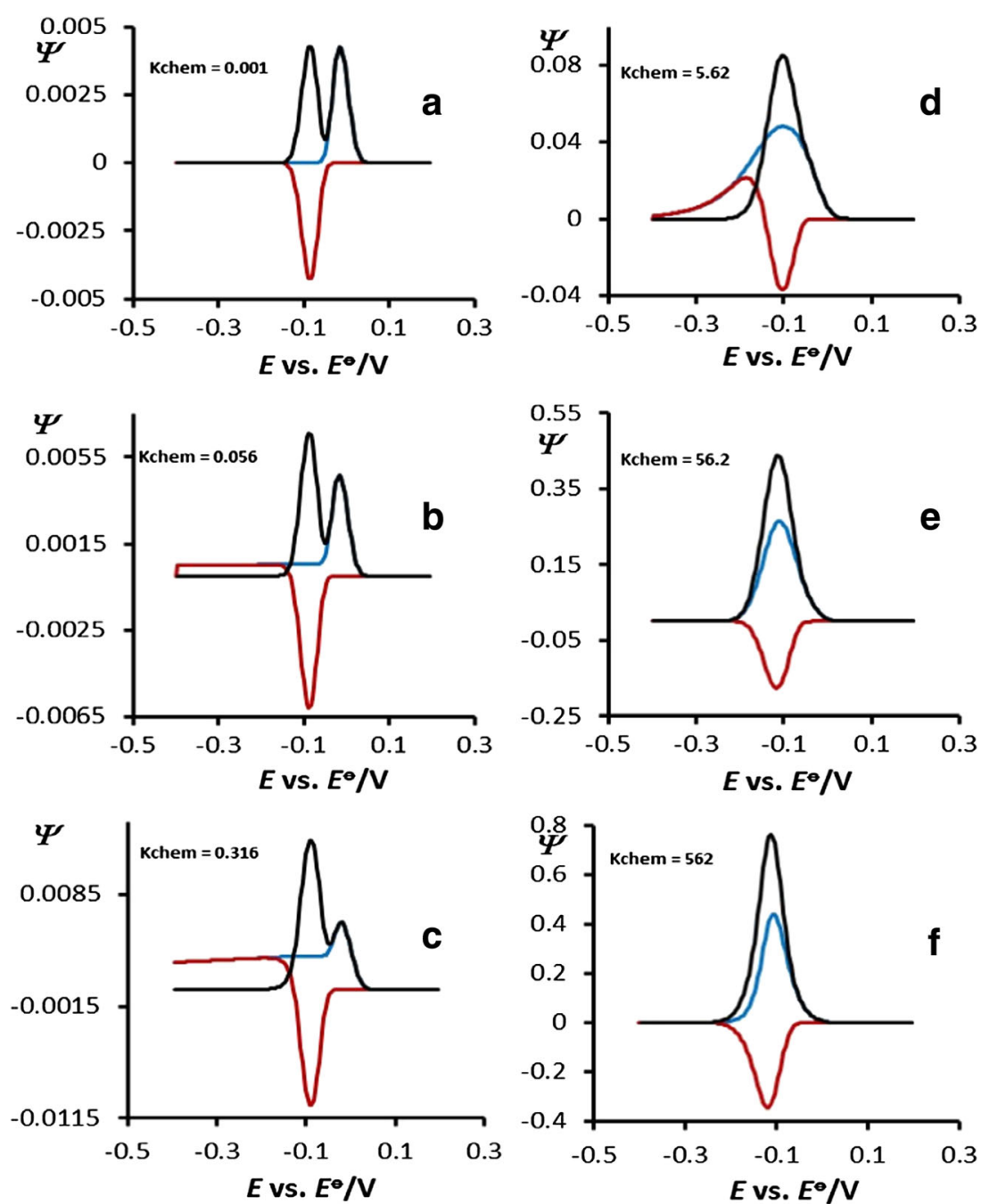

values of $K_{\text {eq. }}$. The expected sigmoid dependences, common for this mechanism [1-4, 19], exist only for $K_{\text {eq }}>1$. However, for $K_{\text {eq }}<1$, the sigmoid curves on Fig. 13a feature a local minimum, roughly in the regions of $-1<\log \left(K_{\text {chem }}\right)<0.1$. The linear portions of sigmoidal curves of Fig. 13a are expanded in Fig. 13b. The slope of the linear part of the function $\mid \Psi_{\text {reduction }}$ $\Psi_{\text {oxidation }} \mid$ vs. $\log \left(K_{\text {chem }}\right)$ is inversely proportional to the value of $K_{\text {eq. }}$. The latter can be additionally used as a criterion for recognizing the $C_{r e v} E$ mechanism. Finally, as explained in [19], the method of measuring the potential separation of the split net peaks as a function of $\log \left(K_{\text {chem }}\right)$ can be explored for the determination of the chemical rate parameter $K_{\text {chem }}$ at the $C_{r e v} E$ mechanism, providing that the values of dimensionless electrode kinetic parameter $K$ and $K_{\text {eq }}$ are known.

\section{Conclusions}

Electrochemical reactions comprise energy exchange between redox active species and an electrically conductive material (working electrode). The kinetics of all electrochemical reactions depends on the type of electrode material, temperature, concentrations of the reactants involved in the redox processes, but also on the applied potential. Commonly, for constant temperature and defined electrode material, relevant kinetic data are evaluated in timedependent experiments (i.e. chronoamperometric experiments in which the current is measured at different time or voltammetric experiment in which the scan rate is varied) $[1-10,17]$. As it has been shown in this work, for surface electrode processes complicated with chemical reactions, evaluating relevant kinetic parameters from timedependent experiments is not an easy task, as the voltammetry is affected by several time-dependent critical parameters. In SWV, the frequency, as the most critical time parameter, affects simultaneously both the kinetics of the electron exchange between the working electrode and the redox couple investigates, but also the kinetics of chemical step, too. Consequently, variation of the frequency gives complex voltammetric patterns that are difficult to be 
Fig. 13 Surface CrevE mechanism: case with fast electron transfer rate. a Dependence of the ratios of absolute values of reduction/ oxidation SWV peak currents as a function of the logarithm of dimensionless chemical parameter $K_{\text {chem }}$. The curves are calculated for four different values of the equilibrium constant of preceding chemical reaction $K$ eq $(K e q$ values are given in the chart). $\mathbf{b}$ Shows the corresponding dependences of the linear part of sigmoidal curves from panel a. The SW voltammograms were simulated for a value of the dimensionless electrode kinetic parameter $K=0.316$. All other simulation parameters are same as in Fig. 1

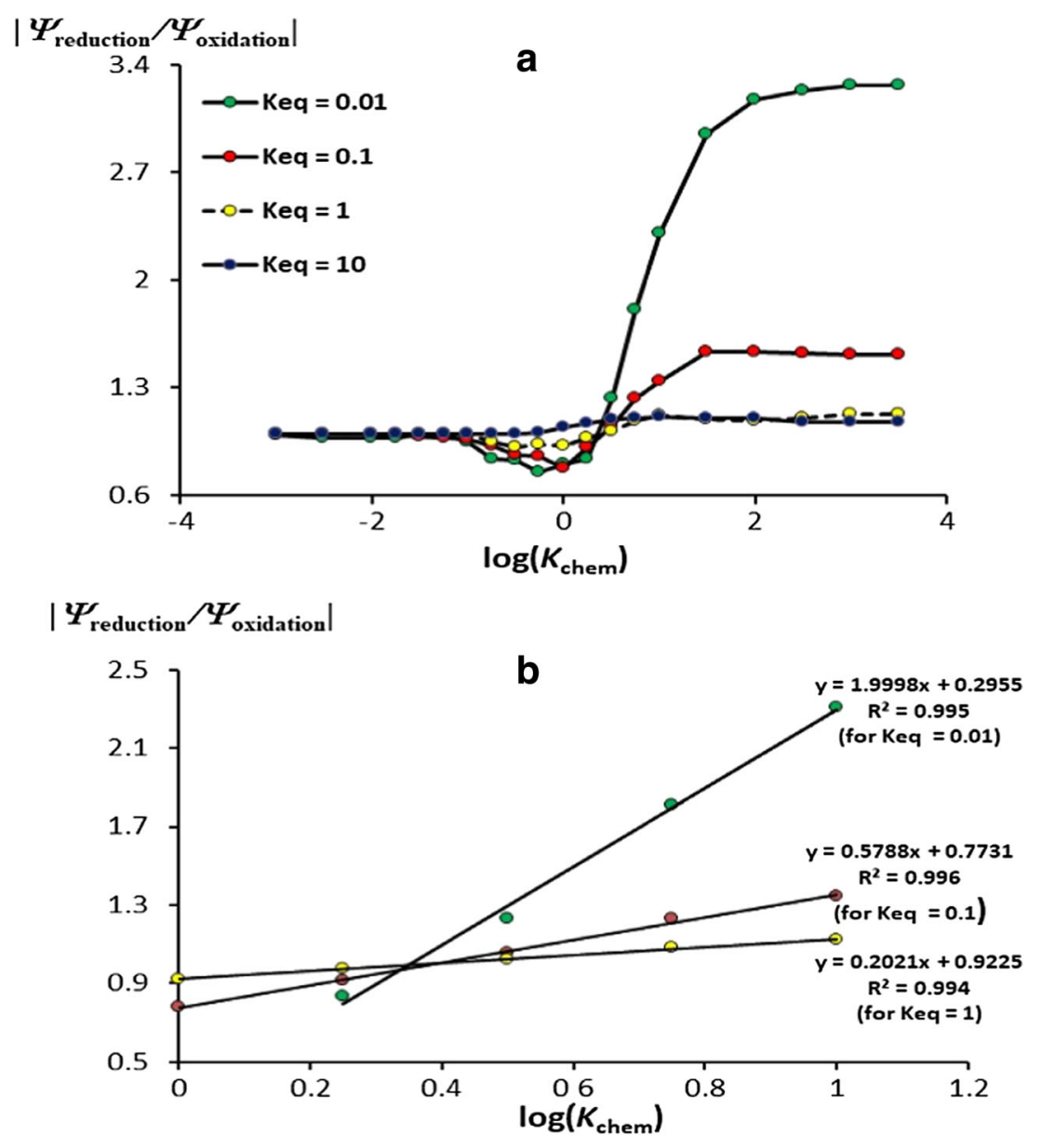

elaborated due to mutual interplay between different kinetic parameters [40, 47-54].

In order to avoid such complexity in real experiments, efforts have been made to develop methods for kinetic measurements with time-independent experiments under conditions of SWV. As shown in the recent work of Mirceski et al. [34], elegant access to the formal rate constant of the electron transfer can be achieved by the method of amplitude-based quasi-reversible maximum, or by measuring the peak potential difference of the forward-tobackward current components $[37,55]$ under constant scan rate. Accordingly, for all electrode mechanisms presented in this work, specific voltammetric features are encountered enabling kinetic and thermodynamic measurements based on the variation of the chemical agent $\mathrm{Y}$ at a constant scan rate and frequency of the voltammetric experiment. Moreover, with the plenty of simulated SW voltammograms presented in this work hints are given for recognizing particular electrode mechanism and qualitative characterization. In the very recent work of Compton et al. [56], the CEC mechanism was considered for the first time in cyclic voltammetry, which will be our next task to be elaborated under condition of SWV.
Acknowledgments We also thank Msci Milkica Janeva for her contribution.

Funding information Valentin Mirceski received support through the NATO Grant No. SPS G5550. Rubin Gulaboski thanks Goce Delcev University Stip for the support via University founded project.

\section{References}

1. Mirceski V, Komorsky-Lovric S, Lovric M (2007) In: Scholz F (ed) Square-wave voltammetry: theory and application, 2nd edn. Springer, Berlin

2. Compton RG, Banks CE (2011) Understanding voltammetry, 2nd edn. Imperial College Press, London

3. Bard AJ, Faulkner LR (2004) Electrochemical methods. Fundamentals and applications, 3rd edition. John Wiley \& Sons, Inc, New York

4. Molina A, Gonzales J (2016) Pulse voltammetry in physical electrochemistry and electroanalysis. In: Scholz F (ed) Monographs in electrochemistry. Springer, Berlin

5. Osteryoung JG, O’Dea JJ (1986) Square-wave voltammetry, electroanalytical chemistry: a series of advances. Marcel Dekker, Inc, New York

6. Mirceski V, Gulaboski R (2014) Recent achievements in squarewave voltammetry (a review). Maced J Chem Chem Eng 33:1-12 
7. Mirceski V, Gulaboski R, Lovric M, Bogeski I, Kappl R, Hoth M (2013) Square-wave voltammetry-a review on the recent progress. Electroanal 25:2411-2422

8. Mirceski V, Lovric M (1997) Split square-wave voltammograms of surface redox reactions. Electroanal 9:1283-1287

9. O'Dea JJ, Osteryoung J, Osteryoung RA (1981) Theory of squarewave voltammetry for kinetic systems. Anal Chem 53:695-701

10. O'Dea JJ, Osteryoung J (1993) Characterization of quasi-reversible surface processes by square-wave voltammetry. Anal Chem 65: 3090-3097

11. Arsmstrong FA (2015) Electrifying metalloenzymes. In: Cho AE, Goddar WA III (eds) Metalloproteins: theory, calculations and experiments. CRC Press, Taylor\&Francis Group, London

12. Armstrong FA (2002) Voltammetry of proteins. In: Bard AJ, Stratmann M, Wilson GS (eds) Encyclopedia of electrochemistry. vol. 9. Wiley VCH, Weinheim

13. Armstrong FA (1997) Applications of voltammetric methods for probing the chemistry of redox proteins. In: Lenaz G, Milazz G (eds) Bioelectrochemistry: principles and practice vol. 5 . Birkhauser Verlag AG, Basel

14. Armstrong FA, Heering HA, Hirst J (1997) Reactions of complex metalloproteins studied by protein-film voltammetry. Chem Soc Rev 26:169-179

15. Leger C, Bertrand P (2008) Direct electrochemistry of redox enzymes as a tool for mechanistic studies. Chem Rev 108:2379-2438

16. Barlett PN (2008) Bioelectrochemistry: fundamentals, experimental techniques and application. Wiley, Chichester

17. Gulaboski R, Mirceski V, Bogeski I, Hoth M (2012) Protein-film voltammetry: electrochemical enzymatic spectroscopy. A review on recent progress. J Solid State Electrochem 16:2315-2328

18. Mirceski V, Gulaboski R (2001) Surface catalytic mechanism in square-wave voltammetry. Electroanal 13:1326-1334

19. Gulaboski R, Mirčeski V, Lovrić M, Bogeski I (2005) Theoretical study of a surface electrode reaction preceded by a homogeneous chemical reaction under conditions of square-wave voltammetry. Electrochem Commun 7:515-522

20. Mirceski V, Gulaboski R (2003) The surface catalytic mechanism: a comparative study with square-wave and cyclic staircase voltammetry. J Solid State Electrochem 7:157-165

21. Mirceski V, Lovric M, Gulaboski R (2001) Theoretical and experimental study of the surface redox reaction involving interactions between the adsorbed particles under conditions of square-wave voltammetry. J Electroanal Chem 515:91-100

22. Gulaboski R, Mirceski V (2015) New aspects of the electrochemical-catalytic (EC') mechanism in square-wave voltammetry. Electrochim Acta 167:219-225

23. Gulaboski R, Mihajlov L (2011) Catalytic mechanism in successive two-step protein-film voltammetry-theoretical study in squarewave voltammetry. Biophys Chem 155:1-9

24. Gulaboski R (2009) Surface ECE mechanism in protein-film voltammetry-a theoretical study under conditions of square-wave voltammetry. J Solid State Electrochem 13:1015-1024 SupplementaryMaterial: https://link.springer.com/article/10.1007/s10008-008-0665-5

25. Gulaboski R (2019) Theoretical contribution towards understanding specific behaviour of "simple" protein-film reactionsinsquarewavevoltammetry. Electroanal 31:545-553

26. Gulaboski R, Janeva M, Maksimova V (2019) New aspects of protein-filmvoltammetry of redox enzymes coupled to follow-up reversible chemical reaction in square-wave voltammetry. Electroanal 31. https://doi.org/10.1002/elan.201900028

27. Gulaboski R, Lovric M, Mirceski V, Bogeski I, Hoth M (2008) Protein-film voltammetry: a theoretical study of the temperature effect using square-wave voltammetry. Biophys Chem 137:49-55

28. Gulaboski R, Lovric M, Mirceski V, Bogeski I, Hoth M (2008) A new rapid and simple method to determine the kinetics of electrode reactions of biologically relevant compounds from the half-peak width of the square-wave voltammograms. Biophys Chem 138: $130-137$

29. Mirceski V, Gulaboski R, Kuzmanovski I (1999) MATHCAD-a tool for numerical calculation of square-wave voltammograms. Bull Chem Technol Maced 18:57-64

30. Komorsky Lovric S, Lovric M (1995) Kinetic measurements of a surface confined redox reaction. Anal Chim Acta 305:248-255

31. Song P, Fisher AC, Wadhawan JD, Cooper JJ, Ward HJ, Lawrence NS (2016) A mechanistic study of the EC' mechanism-the split wave in cyclic voltammetry and square-wave voltammetry. RSC Adv 6:70237-70242

32. Bonazzola C, Gordillo (2016) Advanced analysis for electrode kinetics studies of surface reactions by applying square-wave voltammetry. Electrochim Acta 213:613-619

33. Laborda E, Gonzales Molina A (2014) Recent advances on the theory of pulse techniques: a mini review. Electrochim Acta 43: 25-30

34. Mirceski V, Laborda E, Guziejewski D, Compton R (2013) New approach to electrode kinetic measurements in square-wave voltammetry: amplitude-based quasireversible maximum. Anal Chem 85:5586-5594

35. Dauphin-Durcharme P, Arroyo-Curras N, Kurnik M, Ortega G, Li H, Plaxco KW (2017) Simulation-based approach to determining electron transfer rates using square-wave voltammetry. Langmuir 33:4407-4413

36. Batchelor-McAuley C, Katelhon E, Barnes EO, Compton RG, Laborda E, Molina A (2015) Recent advances in voltammetry. Chem Open 4:224-260

37. Mirceski V, Guzijewski D, Lisichkov K (2013) Electrode kinetics measurements with square-wave voltammetry at a constant scan rate. Electrochim Acta 114:667-673

38. Mirceski V, Guzijewski D, Bozem M, Bogeski I (2016) Characterizing electrode reactions by multisampling the current insquare-wavevoltammetry. Electrochim Acta 213:520-528

39. Jadresko D, Guziejewski D, Mirceski V (2018) Electrochemical faradaic spectroscopy. ChemElectroChem 5:187-194

40. Compton RG, Banks CE (2007) Cyclic voltammetry: coupled homogeneous kinetics and adsorption in: understanding voltammetry. Imperial College Press, London

41. Gulaboski R, Kokoskarova P, Petkovska S (2018) Timeindependent methodology to access Michaelis-Menten constant by exploring electrochemical-catalytic mechanism in protein-film cyclic staircase voltammetry. Croat Chem Acta 91:377-382

42. Mirceski V, Lovric M (2000) Adsorption effects in square-wave voltammetry of an EC mechanism. Croat Chem Acta 73:305-329

43. Mirceski V, Lovric M (2004) EC mechanism of an adsorbed redox couple. Volume vs surface redox reaction. J Electroanal Chem 565: 191-202

44. Garay F, Lovrić M (2002) Square-wave voltammetry of quasireversible electrode processes with coupled homogeneous chemical reactions. J Electroanal Chem 518:91-102

45. Helfrick JC, Mann MA, Bottomley LA (2016) Diagnostic criteria for the characterization of electrode reactions with chemical reactions following electron transfer by cyclic square wave voltammetry. Electrochim Acta 205:20-28

46. Garay F, Lovrić M (2002) Quasi-reversible EC reactions at spherical microelectrodes analysed by square-wave voltammetry. J Electroanal Chem 527:85-92

47. Miler AB, Compton RG (2000) Simulation of square-wave voltammetry. EC and ECE electrode processes. J Phys Chem B 104: $5331-5342$

48. Mirceski V (2001) Square-wave voltammetry of an EC reaction of a partly adsorbed redox couple. J Electroanal Chem 508:138-149

49. Jadresko D, Zelić M (2014) Cyclic multipulse voltammetric techniques. Part II: EC mechanism. J Electroanal Chem 714-715:30-37 
50. Cizmek L, Komorsky-Lovric S, Lovric M (2015) Comparison of cyclic and square-wave voltammetry of irreversible EC mechanism. ChemElectroChem 2:2027-2031

51. Vettorelo SN, Garay F (2018) Theory of square-wave catalytic adsorptive stripping voltammetry. How to obtain mechanistic information from experimental data. J Electroanal Chem 826:125-132

52. Vettorelo SN, Garay F (2016) Adsorptive square-wave voltammetry of quasi-reversible electrode processes with a coupled catalytic chemical reaction. J Solid State Electrochem 20:3271-3278

53. Komorsky-Lovric S, Lovric M (1995) Square-wave voltammetry of quasireversible surface redox reactions. J Electroanal Chem 384: $115-122$

54. Lovrić M, Jadresko D (2010) Theory of square-wave voltammetry of quasireversible electrode reactions using an inverse scan direction. Electrochim Acta 55:948-951
55. Guziejewski D, Mirceski V, Jadresko D (2015) Measuring the electrode kinetics of surface confined electrode reactions at a constant scan rate. Electroanal 27:67-73

56. Lopez-Tenez M, Laborda E, Molina A, Compton RG (2019) Guidelines for the voltammetric study of electrode reactions with coupled chemical kinetics at an arbitrary electrode geometry. Anal Chem 91:6072-6079

Publisher's note Springer Nature remains neutral with regard to jurisdictional claims in published maps and institutional affiliations. 